\title{
Prognostic Value of BIM Deletion in EGFR-Mutant NSCLC Patients Treated with EGFR-TKIs: A Meta-Analysis
}

\author{
Fangfang Lv, ${ }^{1}$ Liang Sun, ${ }^{2}$ Qiuping Yang, ${ }^{1}$ Zheng Pan, ${ }^{1}$ and Yuhua Zhang $\mathbb{D}^{1}$ \\ ${ }^{1}$ Department of Respiratory, Characteristic Medical Center of People's Armed Police Force, Tianjin 300162, China \\ ${ }^{2}$ Department of Immunology, Characteristic Medical Center of People's Armed Police Force, Tianjin 300162, China \\ Correspondence should be addressed to Yuhua Zhang; 1252392543@qq.com
}

Received 10 August 2021; Revised 13 September 2021; Accepted 29 September 2021; Published 13 October 2021

Academic Editor: Federico Carbone

Copyright (C) 2021 Fangfang Lv et al. This is an open access article distributed under the Creative Commons Attribution License, which permits unrestricted use, distribution, and reproduction in any medium, provided the original work is properly cited.

\begin{abstract}
Background. Resistance to epidermal growth factor receptor tyrosine kinase inhibitors (EGFR-TKIs) is inevitable in EGFRmutant non-small-cell lung cancer (NSCLC) patients. A germline $2903 \mathrm{bp}$ deletion polymorphism of Bcl-2-like protein 11 (BIM) causes reduced expression of proapoptotic BH3-only BIM protein and blocks TKI-induced apoptosis of tumor cells. Yet the association between the deletion polymorphism and response to EGFR-TKI treatment remains inconsistent among clinical observations. Thus, we performed the present meta-analysis. Methods. Eligible studies were identified by searching PubMed, Embase, and ClinicalTrials.gov databases prior to March 31, 2021. Hazard ratios (HRs) and 95\% confidence intervals (CIs) of progression-free survival (PFS) and overall survival (OS) and odds ratios (ORs) and 95\% CIs of objective response rate (ORR) and disease control rate (DCR) were calculated by using a random effects model. Sensitivity, metaregression, and publication bias analyses were also performed. Results. A total of 20 datasets (3003 EGFR-mutant NSCLC patients receiving EGFR-TKIs from 18 studies) were included. There were 475 (15.8\%) patients having the 2903-bp intron deletion of BIM and 2528 (84.2\%) wild-type patients. BIM deletion predicted significantly shorter PFS (HR $=1.35,95 \%$ CI: $1.10-1.64, P=0.003)$ and a tendency toward an unfavorable OS ( $\mathrm{HR}=1.22,95 \% \mathrm{CI}: 0.99-1.50, P=0.068)$. Patients with deletion polymorphism had lower ORR (OR $=0.60,95 \% \mathrm{CI}: 0.42-0.85, P=0.004)$ and DCR $(\mathrm{OR}=0.59,95 \% \mathrm{CI}: 0.38-0.90, P=0.014)$ compared with those without deletion. Conclusion. BIM deletion polymorphism may confer resistance to EGFR-TKIs and can be used as a biomarker to predict treatment response to EGFR-TKIs in EGFR-mutant NSCLC patients from Asian populations.
\end{abstract}

\section{Introduction}

Lung cancer is the most prevalent malignant tumor with the highest mortality worldwide, which accounts for $11.6 \%$ of newly diagnosed cancers and $18.4 \%$ of cancer-related deaths in 2018 [1]. Non-small-cell lung cancer (NSCLC) accounts for $80 \sim 85 \%$ of lung cancer, and nearly $70 \%$ of NSCLC patients are diagnosed as having advanced disease $[2,3]$. In recent years, molecular targeted therapy has shown great potentials in improving survivals, response, and quality of life and reducing adverse events and is recommended as the first-line therapy for advanced NSCLC with driven gene mutations according to National Comprehensive Cancer Network (NCCN) guidelines. Meanwhile, for those negative for driven gene mutations, chemoimmunotherapy or immune checkpoint inhibitors (ICIs) are currently the first-line treatment according to programmed cell death ligand 1 (PD-L1) score on tumor tissue.

Epidermal growth factor receptor (EGFR) mutations are important therapeutic targets for NSCLC, which can be found in $10 \%$ of Caucasian patients and 30 40\% of Asian patients $[4,5]$. In vitro experiments showed that NSCLC cell lines with EGFR mutations were hypersensitive to EGFR tyrosine kinase inhibitors (EGFR-TKIs) [6]. Numerous clinical trials demonstrated significantly prolonged progressionfree survival (PFS), overall survival (OS), and higher objective response rate (ORR) in EGFR-mutant NSCLC patients receiving first-/second-generation EGFR-TKIs than those receiving chemotherapy [7-9]. In recent years, the thirdgeneration EGFR-TKI osimertinib, which targets both EGFR-sensitive mutations and T790M-resistant mutation, has showed efficacy superior to other EGFR-TKIs in NSCLC 
patients with EGFR T790M-resistant mutation [10] or with EGFR-sensitive mutations $[11,12]$ and is widely adopted as first-line treatment in current clinical practice.

Despite the great efficacy of EGFR-TKIs, most patients ultimately have a relapse, indicating the development of drug resistance [13]. The acquired resistance to EGFR-TKIs may be mediated by secondary EFGR mutation (T790M for first-/second-generation TKIs, loss of T790M, and secondary C797S mutation for osimertinib), bypass pathway activation (MET/HER2 amplification, KRAS/BRAF/PIK3CA mutation, and RET/FGFR3/BRAF fusion), or small-cell lung cancer transformation $[14,15]$. It is important to identify more biomarkers for TKI resistance and develop new treatment strategies to overcome the resistance.

Bcl-2-like protein 11 (BCL2L11 or BIM) belongs to the B-cell lymphoma-2 (BCL-2) family proteins that play key roles in regulating apoptosis of tumor cells [16]. BIM contains a $\mathrm{BH} 3$ domain which is essential for its proapoptosis activity. Costa et al. found that the upregulation of BIM correlated with gefitinib-induced apoptosis of EGFRmutant lung cancer cells while knockdown of BIM blocked the apoptosis, indicating that BIM mediated TKI-induced apoptosis in lung cancer [17]. Furthermore, $\mathrm{Ng}$ et al. reported that a $2903 \mathrm{bp}$ germline deletion polymorphism between exons 2 and 3 of BIM was associated with inferior response to EGFR-TKIs in EGFR-mutant NSCLC patients [18]. The deletion, causing incorrect splicing of exons 3 and 4 , produces BIM- $\gamma$ isoform that lacks the proapoptotic $\mathrm{BH} 3$ domain [18]. Therefore, this deletion polymorphism of BIM may modify the intrinsic resistance to EGFR-TKIs. Several clinical observations found that EGFR-mutant NSCLC patients carrying the 2903 bp deletion had shorter PFS and OS and were less responsive to EGFR-TKIs than those who did not have the deletion, suggesting that BIM deletion polymorphism may be an independent predictor for prognosis [18-20]. However, the predictive role of the polymorphism remains inconclusive since the results have not been replicated in recent studies [21-23]. Here, we performed a systematic review and meta-analysis to evaluate the association between the 2903 bp deletion polymorphism of BIM and treatment efficacy of EGFR-TKIs in EFGRmutant NSCLC patients.

\section{Methods}

2.1. Literature Search and Selection Criteria. This metaanalysis was in accordance with the Preferred Reporting Items for Systematic Reviews and Meta-Analysis (PRISMA) statement. We searched articles investigating the association between BIM deletion polymorphism and efficacy of EGFRTKIs in EGFR-mutant NSCLC patients in PubMed, Embase, and ClinicalTrials.gov databases prior to March 31, 2021. The following search terms were used: (BIM OR BCL2L11 OR Bcl-2-like protein 11) AND (lung cancer OR nonsmall cell lung cancer OR lung adenocarcinoma OR NSCLC). There was no language restriction. Additional eligible articles were obtained by reviewing the reference lists of relevant review and research articles.
Articles meeting the following criteria were considered eligible: (i) participants were NSCLC cases with EGFR activating mutations; (ii) patients were treated with EGFRTKIs in any line; and (iii) survival outcomes (progressionfree survival (PFS); overall survival (OS)) or treatment response (objective response rate $(\mathrm{ORR})$; disease control rate (DCR)) for BIM deletion and wild-type groups were reported. Reviews, case reports, meeting abstracts, and those without sufficient data to estimate the effect size were discarded.

2.2. Data Extraction. We extracted the following information from each eligible article: first author, publication year, country, line of EGFR-TKIs, sample size, number of BIM deletion carriers, EGFR mutations, clinicopathological characteristics, smoking history, hazard ratio (HR) and corresponding 95\% confidence interval (95\% CI) for survival outcomes, BIM deletion distributions in patients with and without response, and so on. If an article did not report the HRs of survival outcomes, we extracted survival data from corresponding Kaplan-Meier curves using Engauge Digitizer software and estimated the HRs and 95\% CI using the method introduced by Tierney et al. [24]. Data extraction was performed by two independent authors, and discrepancies were solved by full discussion.

2.3. Quality Assessment. The quality of included studies was assessed by using the Newcastle-Ottawa scale (NOS) [25]. NOS contains 3 domains with 8 items which are awarded with a total of 9 stars. Studies with 7 or more stars were considered of high quality.

2.4. Statistical Analysis. The between-study heterogeneity was assessed by $I^{2}$ which indicated low $(<25 \%)$, medium (25 50\%), and high (>50\%) heterogeneity, respectively. Considering the existence of heterogeneity, we applied a random effects model to all of the pooled analyses, which may generate more conservative results with wider confidence intervals than using a fixed effects model. The pooled HR for survival outcomes and odds ratio (OR) for response was calculated. In addition, we stratified the analysis by several moderators, including country (South Korea, China, and other countries), HR estimates (reported, estimated), and survival analysis (univariate, multivariate). Furthermore, to explore the other potential sources of heterogeneity, we performed metaregression analysis which allowed us to investigate the impact of several factors on pooled effect size. These factors included publication year, sample size, BIM deletion frequency, percent of adenocarcinoma cases, percent of first-line EGFR-TKI-treated patients, percent of ever-smoking patients, percent of male, percent of patients with Eastern Cooperative Oncology Group performance status (ECOGPS $) \geq 2$, percent of stage IV or recurrent patients, and percent of patients harboring classic EGFR mutations (exon 19 deletions and exon 21 L858R). We also performed sensitivity analysis by excluding each study one at a time and pooling the others to assess the impact of a single study on the pooled effect size. Finally, we assessed the publication bias by a funnel plot and Egger's test. The meta-analysis was 


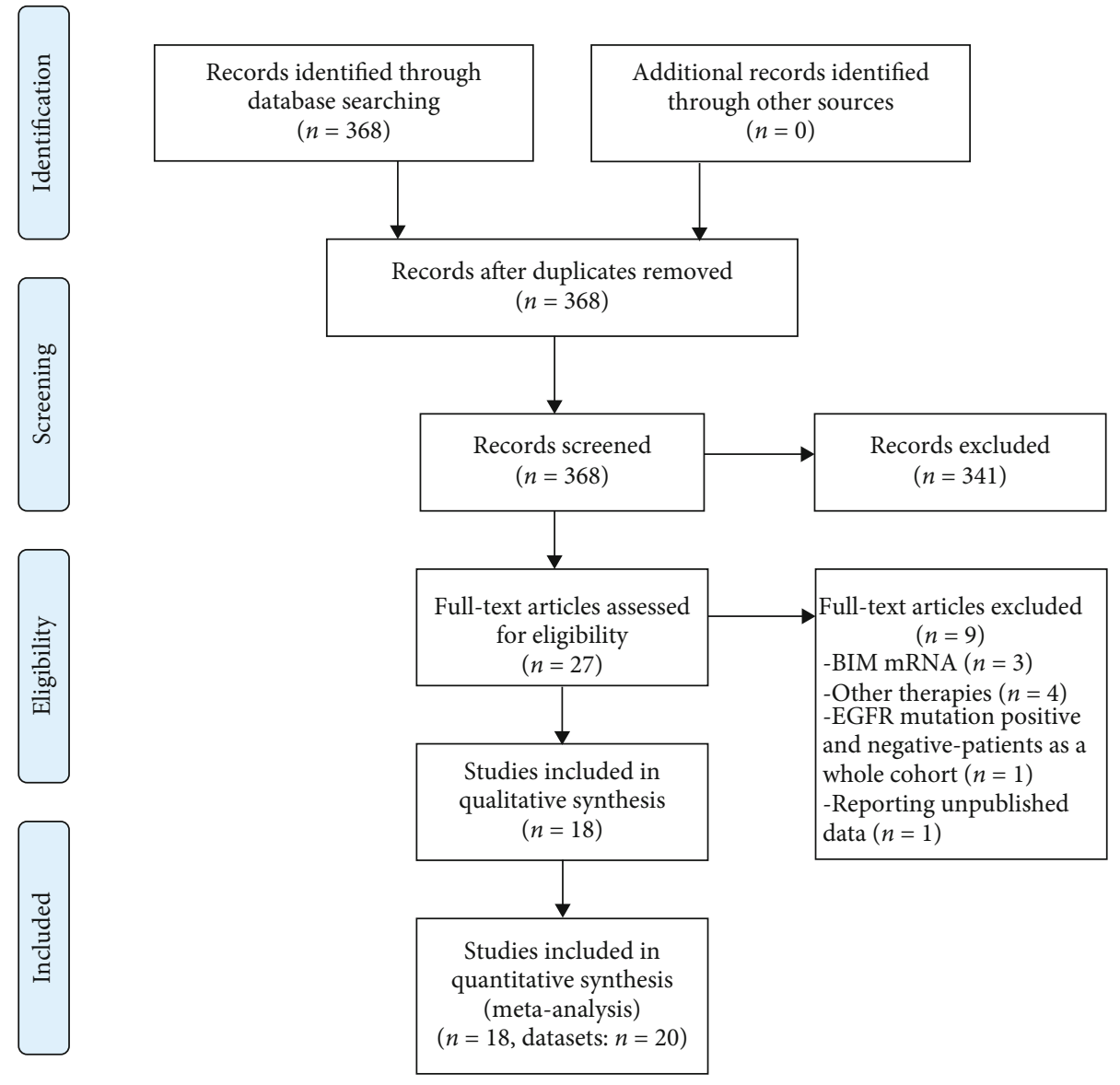

FIgURE 1: Flowchart of literature search.

performed by using Stata 12.0 (Stata Corporation, TX, USA). The threshold of statistical significance was set as $P<0.05$.

\section{Results}

3.1. Characteristics of Eligible Studies. Initially, a total of 368 articles were obtained by literature search, of which 341 were obviously not relevant and excluded. For the remaining candidate articles, 3 studied BIM mRNA expression [26-28], 4 reported the other therapies (resection, chemotherapy, radiotherapy, or crizotinib) [29-32], and 1 analyzed EGFR-mutant and EGFR-wild-type patients as a whole cohort [33]. Besides, 1 study reported 3 unpublished datasets that were requested from the other researchers [34]. Yet we could not determine whether they were duplicated with the other studies published later and had to discard them. Thus, these 9 studies were excluded. For 3 studies that also included EGFR-mutant and EGFR-wild-type patients simultaneously, we could extract the data from EGFR-mutant patients [19, $22,35]$. For two studies, each reported two unrelated cohorts $[21,23]$. Finally, 20 datasets from 18 studies [18-23, 35-46] exploring the association between BIM deletion polymorphism and EGFR-TKI efficacy in EGFR-mutant NSCLC patients were included in our meta-analysis (Figure 1).

Among the 3003 EGFR-mutant NSCLC patients included in our meta-analysis, 475 had the $2903 \mathrm{bp}$ intron deletion of BIM. The frequencies of BIM deletion ranged between $9.6 \%$ and $26.4 \%$. All of the studies enrolled stage III, IV, or recurrent patients except one including patients of all stages [35] and one not reporting stages [46]. The first-generation TKIs including gefitinib and erlotinib were the most frequently used while afatinib and icotinib were also given to some patients. Notably, Li et al. enrolled patients positive for EGFR T790M-resistant mutation and treated with osimertinib [45]. Only one study was prospectively designed [19] while the others were all retrospective. For survival outcomes, all of the 20 datasets reported PFS and 13 reported OS. For response, 14 and 12 datasets reported ORR and DCR, respectively. All studies were awarded with 7 or more stars and were considered to be of high quality. The characteristics of included studies for survival and response outcomes are shown in Tables 1 and 2, respectively.

3.2. BIM Deletion Predicted Unfavorable PFS and OS. Twenty datasets comprising 3003 patients explored the predictive role of BIM deletion in PFS (Table 3). Meta-analysis demonstrated that BIM deletion carriers had significantly shorter PFS than wide-type carriers $(\mathrm{HR}=1.35,95 \% \mathrm{CI}$ : $1.10-1.64, P=0.003$, Figure 2). Even if two outliers with $\mathrm{HR} \geq 3.00$ were excluded $[42,44]$, the association was still significant $\quad(H R=1.24,95 \%$ CI $1.04-1.49, \quad P=0.020)$, 
TABLE 1: Characteristics of included studies for survival analysis.

\begin{tabular}{|c|c|c|c|c|c|c|c|c|}
\hline Author & Year & Country & $\begin{array}{l}\text { BIM deletion/ } \\
\text { total }\end{array}$ & $\begin{array}{l}\text { Line of } \\
\text { EGFR-TKIs }\end{array}$ & NSCLC stage & $\begin{array}{l}\text { Median PFS, months } \\
\quad(\text { deletion/WT })\end{array}$ & $\begin{array}{l}\text { Median OS, months } \\
\quad(\text { deletion/WT) }\end{array}$ & $\begin{array}{l}\text { NOS } \\
\text { stars }\end{array}$ \\
\hline $\mathrm{Ng} \mathrm{KP}$ & 2012 & Singapore & $26 / 141$ & First or more & $\begin{array}{l}\text { III, IV, } \\
\text { recurrent }\end{array}$ & $6.6 / 11.9$ & NR & 7 \\
\hline Lee JK & 2013 & $\begin{array}{l}\text { South } \\
\text { Korea }\end{array}$ & $21 / 193$ & First or more & $\begin{array}{l}\text { IIIB, IV, } \\
\text { recurrent }\end{array}$ & $11.9 / 11.3$ & NR & 8 \\
\hline Zheng L & 2013 & China & $21 / 123$ & $\begin{array}{l}\text { Second or } \\
\text { more }\end{array}$ & IIIB, IV & $3.5 / 6.0$ & NR & 8 \\
\hline Isobe $\mathrm{K}$ & 2014 & Japan & $13 / 70$ & First or more & IV, recurrent & 7.6/17.8 & $39.2 / 45.4$ & 7 \\
\hline Zhao MC & 2014 & China & $16 / 166$ & First or more & IIIB, IV & $4.7 / 11.0$ & NR & 9 \\
\hline Lee JH & 2014 & China & $16 / 80$ & First & IIIB, IV & $7.4 / 9.4$ & $18.3 / 24.9$ & 7 \\
\hline Zhong J & 2014 & China & $24 / 159$ & First or more & I-IV & $7.3 / 9.5$ & NR & 7 \\
\hline Lee JY cohort 1 & 2015 & $\begin{array}{l}\text { South } \\
\text { Korea }\end{array}$ & $32 / 205$ & First or more & $\begin{array}{l}\text { IIIB, IV, } \\
\text { recurrent }\end{array}$ & $11.9 / 10.9$ & $31.2 / 30.3$ & 7 \\
\hline Lee JY cohort 2 & 2015 & $\begin{array}{l}\text { South } \\
\text { Korea }\end{array}$ & $10 / 69$ & First or more & $\begin{array}{l}\text { IIIB, IV, } \\
\text { recurrent }\end{array}$ & $11.6 / 9.7$ & NR & 7 \\
\hline Wu SG & 2016 & China & $52 / 327$ & NR & IV & $10.5 / 8.5$ & NR & 8 \\
\hline Cardona AF & 2016 & Columbia & $14 / 89$ & First & IIIA, IIIB, IV & $10.8 / 21.7$ & $15.5 / 34.0$ & 7 \\
\hline Sun $S$ & 2017 & China & $37 / 140$ & First or more & III, IV & $21 / 17$ & $34 / 33$ & 7 \\
\hline Qian K & 2017 & China & $14 / 85$ & First & IIIB, IV & $7.1 / 12.8$ & NR & 7 \\
\hline Xia JJ & 2017 & China & $43 / 245$ & First or more & $\begin{array}{l}\text { IIIB, IV, } \\
\text { recurrent }\end{array}$ & $22 / 38$ & $24 / 39$ & 8 \\
\hline Wang F & 2019 & China & $18 / 169$ & First or more & $\begin{array}{l}\text { IIIB, IV, } \\
\text { recurrent }\end{array}$ & NR & NR & 9 \\
\hline Incharoen $\mathrm{P}$ & 2019 & Thailand & $20 / 97$ & First or more & IV, recurrent & $8.6 / 8.9$ & $25.8 / 28.9$ & 8 \\
\hline $\begin{array}{l}\text { Liu SY } \\
\text { CTONG0901 }\end{array}$ & 2020 & China & $22 / 194$ & First or more & IIIB, IV & $10.5 / 11.2$ & $20.5 / 20.5$ & 7 \\
\hline Liu SY GLCI & 2020 & China & $24 / 141$ & First or more & IIIB, IB & $10.1 / 11.6$ & $58.5 / 45.0$ & 7 \\
\hline Ariyasu R & 2020 & Japan & $27 / 167$ & First or more & NR & $10.3 / 10.4$ & $38.4 / 31.6$ & 8 \\
\hline $\mathrm{Li} \mathrm{XZ}^{\#}$ & 2021 & China & $25 / 143$ & $\begin{array}{l}\text { Second or } \\
\text { more }\end{array}$ & IIIB, IV & $8.3 / 10.5$ & $15.9 / 25.2$ & 8 \\
\hline
\end{tabular}

\#All patients were positive for EGFR T790M and received osimertinib. EGFR-TKIs: epidermal growth factor receptor tyrosine kinase inhibitors; NSCLC: nonsmall-cell lung cancer; PFS: progression-free survival; OS: overall survival; WT: wild-type BIM; NOS: Newcastle-Ottawa scale; NR: not reported.

indicating that the result was robust. Stratified analysis showed that BIM deletion predicted unfavorable PFS in the Chinese population $(\mathrm{HR}=1.32,95 \%$ CI $1.05-1.66, P=$ $0.019)$ and the other populations (HR $=1.80,95 \%$ CI 1.09 2.99, $P=0.022$ ) but not in the South Korean population $(\mathrm{HR}=0.84,95 \%$ CI $0.61-1.17, P=0.310)$.

The association between BIM deletion and OS was evaluated in 13 datasets (Table 4) with 1830 EGFRmutant NSCLC patients. Our analysis indicated that BIM deletion was related to a shorter OS, but the association was not significant $(\mathrm{HR}=1.22,95 \% \mathrm{CI}: 0.99-1.50, P=$ 0.068 , Figure 3 ). Subgroup analysis in the Chinese population rather than the other populations demonstrated a significant association between BIM deletion and OS $(\mathrm{HR}=1.30,95 \% \mathrm{CI}: 1.06-1.60, P=0.013)$.

3.3. BIM Deletion Predicted Lower Response Rates. The association between BIM deletion and treatment response to EGFR-TKIs was also analyzed (Table 5). Our results demonstrated that BIM deletion polymorphism was associated with lower objective response rate $(\mathrm{OR}=0.60,95 \% \mathrm{CI}$ : $0.42-0.85, P=0.004$, Figure 4) and disease control rate $(\mathrm{OR}=0.59,95 \% \mathrm{CI}: 0.38-0.90, P=0.014$, Figure 5). If two outliers with $\mathrm{OR} \leq 0.20$ were excluded $[36,44]$, the association for ORR was still significant (OR $=0.71$, 95\% CI 0.52 $0.96, P=0.025, I^{2}=0$ ), indicating that the result was robust. The significant associations were found in the subgroup of the Chinese population that carriers of BIM deletion were less likely to achieve objective response (OR $=0.50,95 \%$ CI $0.35-0.71, P<0.001)$ or disease control $(\mathrm{OR}=0.48$, 95\% CI $0.30-0.77, P=0.002$ ).

3.4. Metaregression Analysis, Sensitivity Analysis, and Publication Bias. The results of metaregression analysis are shown in Supplementary Table 1. Sample size was suggested as a modulator for the effect size of PFS at borderline significance $(P=0.040)$. The other factors were not the source of between-study heterogeneity according to metaregression analysis. Yet subgroup analysis stratified by country showed that there was low between-study 
TABLE 2: Characteristics of included studies for treatment response to EGFR-TKIs.

\begin{tabular}{|c|c|c|c|c|c|c|}
\hline Author & Year & $\mathrm{ORR}^{\#}$ & Non-ORR ${ }^{\#}$ & $\mathrm{DCR}^{\&}$ & Non-DCR ${ }^{\&}$ & Response criteria \\
\hline Zheng L & 2013 & $3 / 33$ & $18 / 69$ & $12 / 77$ & $9 / 25$ & RECIST v1.1 \\
\hline Isobe $\mathrm{K}$ & 2014 & $8 / 37$ & $5 / 20$ & $13 / 52$ & $0 / 5$ & NR \\
\hline Zhao MC & 2014 & $4 / 99$ & $12 / 51$ & $10 / 122$ & $6 / 28$ & RECIST v1.1 \\
\hline Lee JY cohort 1 & 2015 & $29 / 146$ & $3 / 27$ & $30 / 163$ & $2 / 10$ & RECIST v1.1 \\
\hline Lee JY cohort 2 & 2015 & $7 / 45$ & $3 / 14$ & $10 / 55$ & $0 / 4$ & RECIST v1.1 \\
\hline Cardona AF & 2016 & $5 / 55$ & $9 / 20$ & NR & NR & NR \\
\hline Sun $S$ & 2017 & $16 / 63$ & $17 / 37$ & $31 / 97$ & $2 / 3$ & RECIST v1.1 \\
\hline Qian K & 2017 & $4 / 27$ & $10 / 41$ & $12 / 63$ & $2 / 5$ & RECIST \\
\hline Wang F & 2019 & $4 / 64$ & $14 / 83$ & $14 / 137$ & $4 / 10$ & RECIST v1.0 \\
\hline Incharoen $\mathrm{P}$ & 2019 & $13 / 41$ & $7 / 36$ & $18 / 65$ & $2 / 12$ & RECIST v1.1 \\
\hline Liu SY CTONG0901 & 2020 & $12 / 97$ & $10 / 75$ & $20 / 152$ & $2 / 20$ & NR \\
\hline Liu SY GLCI & 2020 & $13 / 71$ & $11 / 46$ & $22 / 113$ & $2 / 4$ & NR \\
\hline Ariyasu R & 2020 & $22 / 117$ & $5 / 23$ & NR & NR & RECIST v1.1 \\
\hline Li XZ & 2021 & $7 / 62$ & $18 / 56$ & $22 / 106$ & $3 / 12$ & RECIST v1.1 \\
\hline
\end{tabular}

"Number of patients who achieved objective response (ORR) and who did not achieve objective response (non-ORR) in the BIM deletion group/wild-type group, respectively. ${ }^{\&}$ Number of patients who achieved disease control (DCR) and who did not achieve disease control (non-DCR) in the BIM deletion group/wild-type group, respectively. ORR: objective response rate; DCR: disease control rate; RECIST: Response Evaluation Criteria in Solid Tumors; NR: not reported.

TABLE 3: Meta-analysis of BIM deletion polymorphism associated with PFS.

\begin{tabular}{|c|c|c|c|c|c|c|}
\hline Subgroup & No. of studies & BIM deletion/total & $I^{2}(\%)$ & Pooled HR & $95 \% \mathrm{CI}$ & $P$ \\
\hline Overall & 20 & $475 / 3003$ & 63.1 & 1.35 & $1.10-1.64$ & 0.003 \\
\hline \multicolumn{7}{|l|}{ Country } \\
\hline South Korea & 3 & $63 / 467$ & 0 & 0.84 & $0.61-1.17$ & 0.310 \\
\hline China & 12 & $312 / 1972$ & 58.9 & 1.32 & $1.05-1.66$ & 0.019 \\
\hline Others & 5 & $100 / 564$ & 72.8 & 1.80 & $1.09-2.99$ & 0.022 \\
\hline \multicolumn{7}{|l|}{ HR estimates } \\
\hline Reported & 14 & $365 / 2275$ & 69.3 & 1.39 & $1.07-1.81$ & 0.013 \\
\hline Estimated & 6 & $110 / 728$ & 44.6 & 1.28 & $0.95-1.71$ & 0.100 \\
\hline \multicolumn{7}{|l|}{ Survival analysis } \\
\hline Univariate & 13 & $333 / 2104$ & 44.8 & 1.10 & $0.91-1.33$ & 0.331 \\
\hline Multivariate & 7 & $142 / 899$ & 54.8 & 1.89 & $1.37-2.62$ & $<0.001$ \\
\hline
\end{tabular}

PFS: progression-free survival; HR: hazard ratio. All HRs were pooled by a random effects model.

heterogeneity in studies from China. Sensitivity analysis showed that none of the included studies had significant impact on the pooled effect size. The funnel plot for PFS was obviously asymmetric which indicated potential publication bias (Egger's test, $P=0.009$ ), while the funnel plots for OS, ORR, and DCR were all symmetric (Figure 6).

\section{Discussion}

BIM encodes a BH3-only protein crucial for BCL-2-induced apoptosis of tumor cells. The 2903 bp deletion polymorphism leads to significantly reduced expression or absence of functional protein containing the $\mathrm{BH} 3$ domain and interrupts the apoptosis process of EGFR-mutant tumor cells induced by EGFR-TKIs [18]. The present meta-analysis of clinical observations demonstrated that the presence of deletion was significantly associated with shorter PFS, lower ORR and DCR, and a tendency toward an unfavorable OS. In particular in the Chinese population, BIM deletion polymorphism predicted inferior survival and treatment response. Therefore, the BIM deletion polymorphism confers resistance to EGFR-TKIs and can be used as a predictor of treatment efficacy and prognosis of EGFR-mutant NSCLS patients treated with EGFR-TKIs from Asian populations.

In addition to the deletion polymorphism, the expression levels of BIM mRNA were also associated with responsiveness to EGFR-TKIs. NSCLC patients with high expression levels had significantly prolonged PFS and OS than those with low/intermediate levels [26-28]. Either the polymorphism or the mRNA expression may confer resistance to TKIs through reducing the product of proapoptotic BH3-containing BIM protein. One possible 


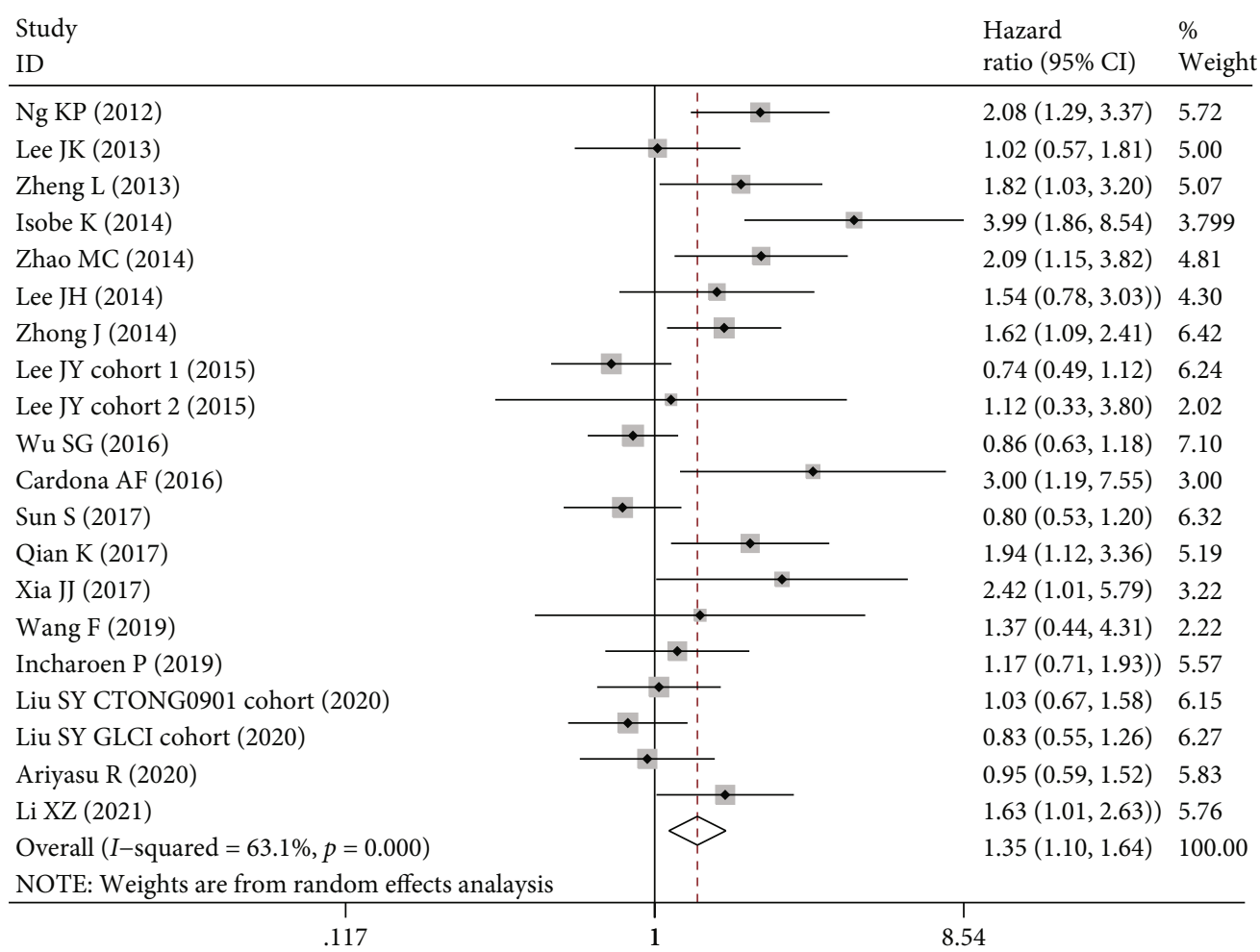

FIGURE 2: Forest plot of BIM deletion polymorphism associated with progression-free survival in EGFR-mutant NSCLC patients treated with EGFR-TKIs.

TABLE 4: Meta-analysis of BIM deletion polymorphism associated with OS.

\begin{tabular}{|c|c|c|c|c|c|c|}
\hline Subgroup & No. of studies & BIM deletion/total & $I^{2}(\%)$ & Pooled HR & $95 \% \mathrm{CI}$ & $P$ \\
\hline Overall & 13 & $303 / 1830$ & 43.0 & 1.22 & $0.99-1.50$ & 0.068 \\
\hline \multicolumn{7}{|l|}{ Country } \\
\hline China & 7 & $187 / 1133$ & 12.5 & 1.30 & $1.06-1.60$ & 0.013 \\
\hline Others & 6 & $116 / 697$ & 58.1 & 1.12 & $0.75-1.69$ & 0.579 \\
\hline \multicolumn{7}{|l|}{ HR estimates } \\
\hline Reported & 8 & $216 / 1255$ & 59.6 & 1.25 & $0.90-1.74$ & 0.178 \\
\hline Estimated & 5 & $87 / 575$ & 0 & 1.21 & $0.96-1.53$ & 0.101 \\
\hline \multicolumn{7}{|l|}{ Survival analysis } \\
\hline Univariate & 11 & $262 / 1574$ & 11.0 & 1.22 & $1.02-1.45$ & 0.029 \\
\hline Multivariate & 2 & $41 / 256$ & 89.2 & 1.47 & $0.31-6.92$ & 0.622 \\
\hline
\end{tabular}

OS: overall survival; HR: hazard ratio. All HRs were pooled by a random effects model.

strategy to overcome the resistance and restore the response to TKIs is adding $\mathrm{BH} 3$-mimetic drug or histone deacetylase (HDAC) inhibition. In vitro experiments revealed that the addition of BH3-mimetic drug ABT-737 with imatinib enhanced the TKI-induced apoptosis and cell death in deletion-containing cells $[18,47]$. The other studies demonstrated that the HDAC inhibitor vorinostat could circumvent TKI resistance in EGFR-mutant NSCLC cell lines harboring BIM deletion polymorphism $[48,49]$. A phase I study evaluated the effect of vorinostat plus gefitinib in BIM deletion/EGFR mutation double-positive NSCLC patients [50]. The median PFS was 5.2 months, and DCR at 6 weeks was
83.3\% [50]. However, the therapeutic effect of the combination of $\mathrm{BH} 3$-mimetic drugs or HDAC inhibitors with EGFRTKIs in patients developing BIM deletion polymorphismmediated resistance needs to be validated by more clinical trials.

Besides the proapoptosis activity, BIM may play a crucial role in tissue vascularization. $\operatorname{Bim}(-/-)$ retinal endothelial cells have increased proliferation, migration, and vascular endothelial growth factor (VEGF) expression [51]. In lung endothelial cells, lack of Bim expression increased migration [52]. The conditional lack of Bim in mice attenuates hyaloid vessel regression and promotes retinal vascular remodeling 


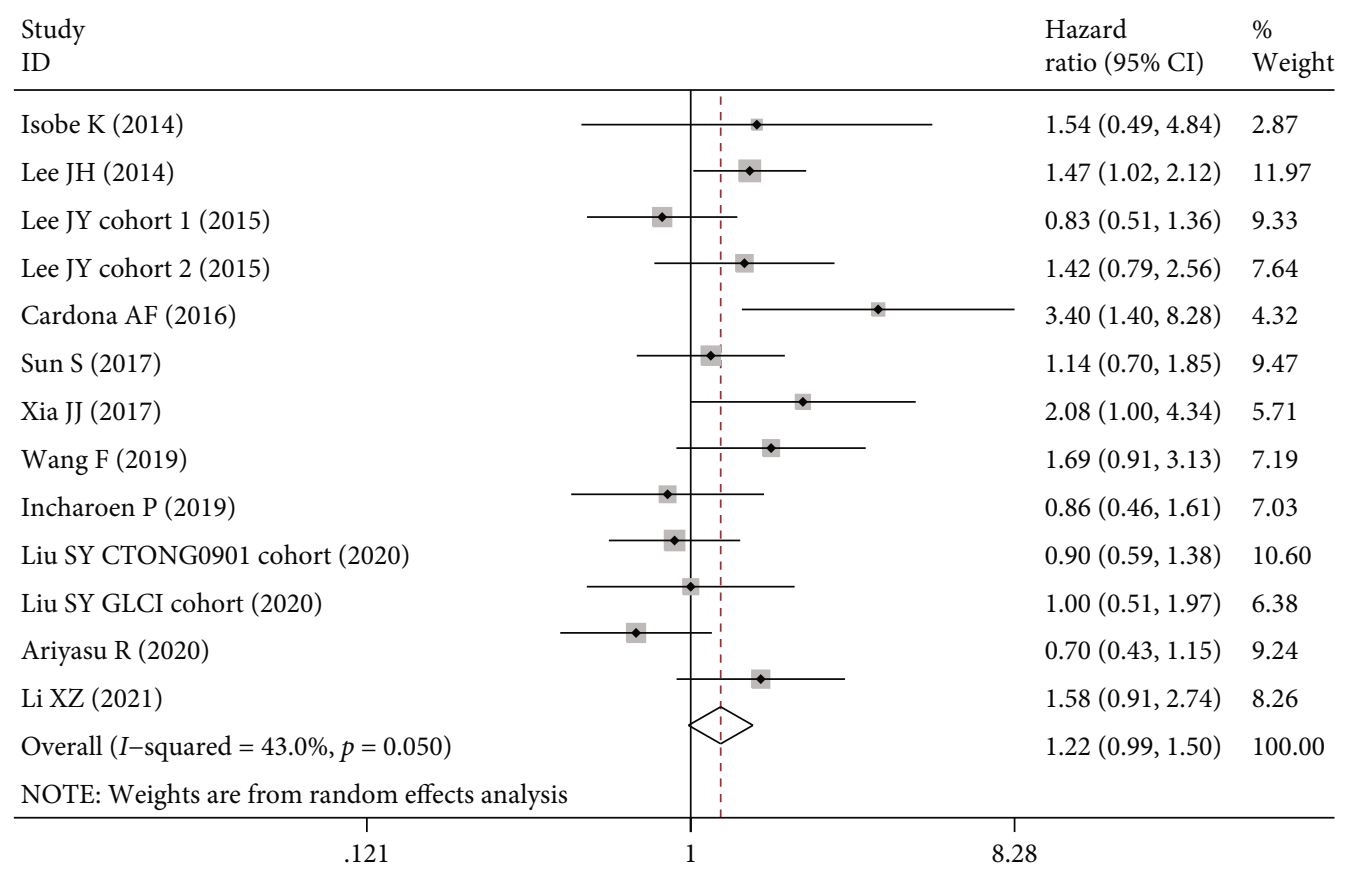

FIGURE 3: Forest plot of BIM deletion polymorphism associated with overall survival in EGFR-mutant NSCLC patients treated with EGFRTKIs.

TABLE 5: Meta-analysis of BIM deletion polymorphism associated with response to EGFR-TKIs.

\begin{tabular}{|c|c|c|c|c|c|c|}
\hline Response & No. of studies & BIM deletion/total & $I^{2}(\%)$ & Pooled OR & $95 \% \mathrm{CI}$ & $P$ \\
\hline \multicolumn{7}{|l|}{ ORR } \\
\hline Overall & 14 & $289 / 1844$ & 30.4 & 0.60 & $0.42-0.85$ & 0.004 \\
\hline China & 8 & $173 / 1147$ & 1.9 & 0.50 & $0.35-0.71$ & $<0.001$ \\
\hline Others & 6 & $116 / 697$ & 40.4 & 0.85 & $0.45-1.59$ & 0.605 \\
\hline \multicolumn{7}{|l|}{ DCR } \\
\hline Overall & 12 & $248 / 1588$ & 0 & 0.59 & $0.38-0.90$ & 0.014 \\
\hline China & 8 & $173 / 1147$ & 0 & 0.48 & $0.30-0.77$ & 0.002 \\
\hline Others & 4 & $75 / 441$ & 0 & 1.40 & $0.52-3.75$ & 0.504 \\
\hline
\end{tabular}

ORR: objective response rate; DCR: disease control rate; OR: odds ratio.

[53]. These findings suggest a relevance between BIM and angiogenesis. Previous clinical trials demonstrated that erlotinib combined with antiangiogenic drugs, such as ramucirumab and bevacizumab, increased PFS but not treatment response in advanced NSCLC $[54,55]$. A recent retrospective study analyzed the clinical efficacy of EGFR-TKI plus bevacizumab (VEGF inhibitor) versus EGRK-TKI alone in advanced NSCLC patients with EFGR mutations and BIM deletion and found that the addition of bevacizumab resulted in significantly higher ORR, longer PFS, and a tendency toward a favorable OS [56]. It seems that the combination of EGFR-TKIs and antiangiogenic agents may be more effective in patients with BIM deletion polymorphism, which needs comparison to patients negative for the polymorphism in the future. Nonetheless, this provides a possible strategy to improve treatment response to EFGR-TKIs by adding VEGR inhibitors in this group of patients.
Apart from EGFR-TKIs, BIM deletion polymorphism may also mediate the resistance to crizotinib, the firstgeneration anaplastic lymphoma kinase (ALK) TKI. ALK fusion-positive NSCLC patients with BIM deletions had a significantly shorter PFS and lower ORR than those without the polymorphism [57]. However, Lin et al. did not found a positive association between the polymorphism and PFS or OS [29]. More evidence needs to be collected to determine the predictive role of BIM deletion polymorphism in ALK TKI-treated NSCLC patients.

Despite the prognostic value, the deletion polymorphism can only be used as a biomarker in the Asian population since the polymorphism is not found in Caucasians or Africans [18]. Studies included in our meta-analysis were mainly conducted in Singapore, China, Japan, South Korea, and Thailand, while only one was in Columbia with Hispanic patients [44]. The prevalence of deletion polymorphism 


\begin{tabular}{l} 
Study \\
ID \\
\hline Zheng L (2013) \\
Isobe K (2014) \\
Zhao MC (2014) \\
Lee JY cohort 1 (2015) \\
Lee JY cohort 2 (2015) \\
Cardona AF (2016) \\
Sun S (2017) \\
Qian K (2017) \\
Wang F (2019)
\end{tabular}

FIGURE 4: Forest plot of BIM deletion polymorphism associated with objective response rate in EGFR-mutant NSCLC patients treated with EGFR-TKIs.

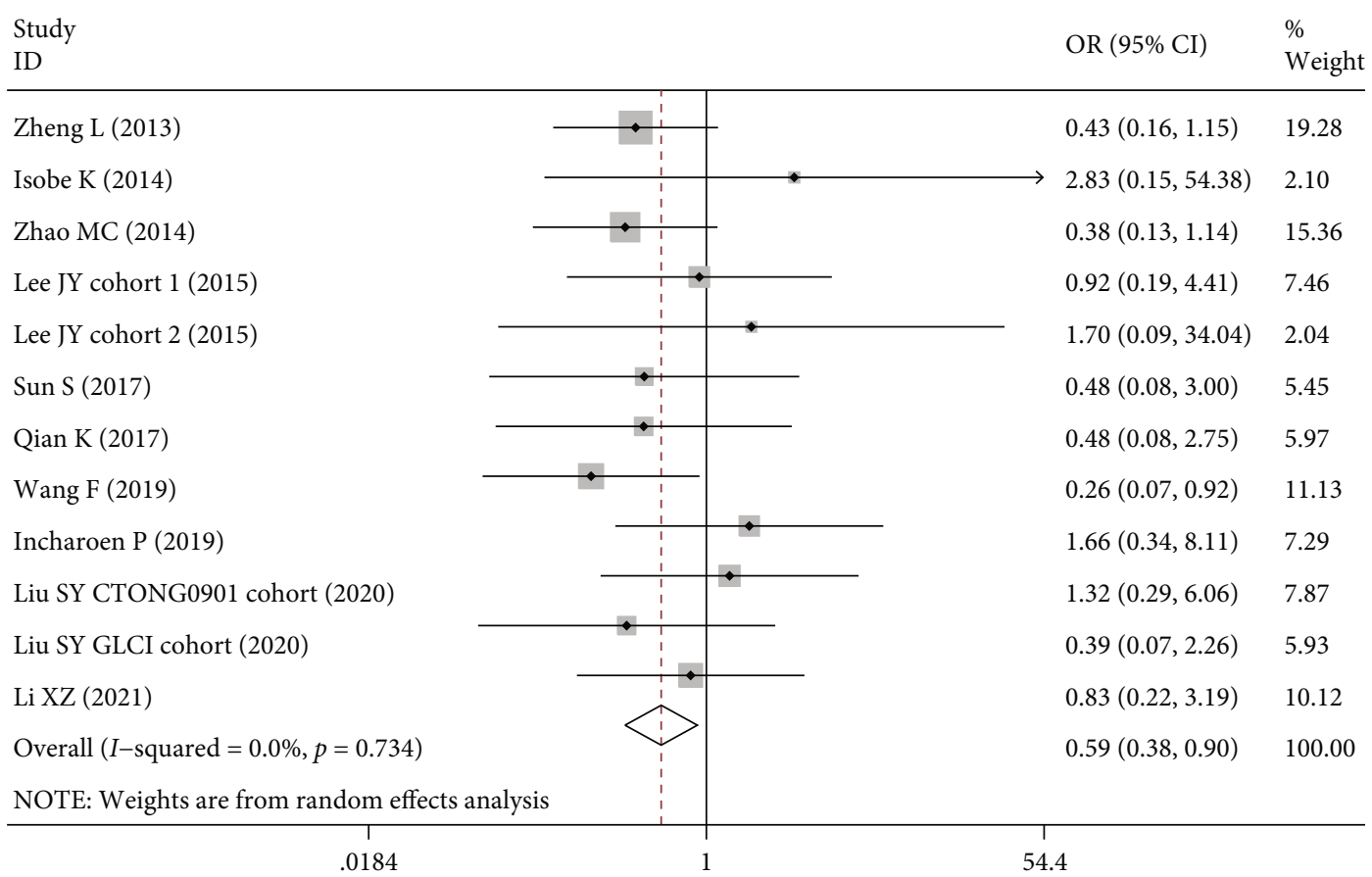

FIGURE 5: Forest plot of BIM deletion polymorphism associated with disease control rate in EGFR-mutant NSCLC patients treated with EGFR-TKIs

varied between $9.6 \%$ and $26.4 \%$ in these studies, and the mean frequency was $15.8 \%$ (475/3003).

Compared with previous meta-analyses [39, 58-61], the present study has several strengths. Firstly, our study exclu- sively included EGFR-mutant patients to keep individual homogeneity while several previous meta-analyses did not carefully discriminate EGFR mutation status [39, 58] when screening eligible studies. Secondly, our study had the largest 


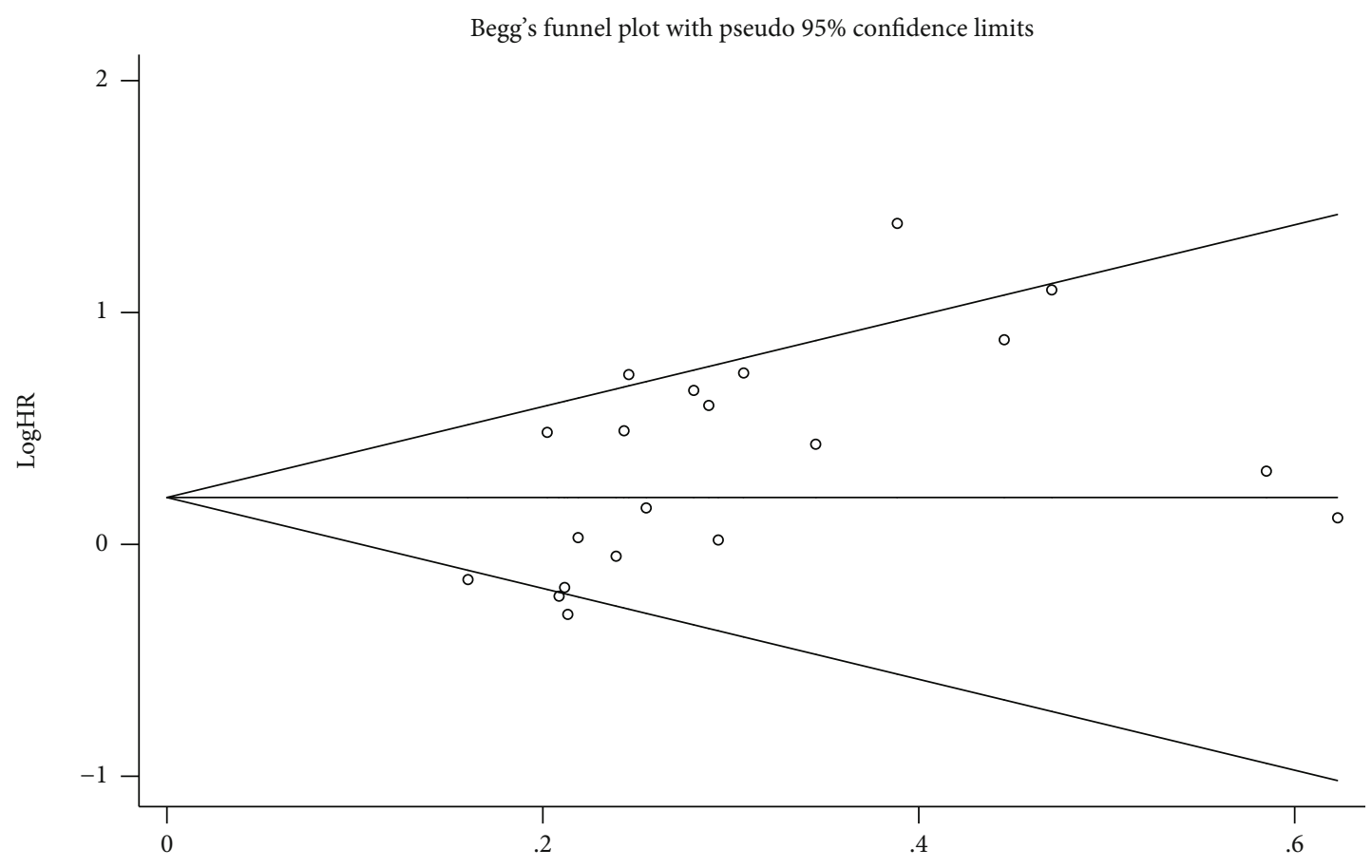

s.e. of: $\log H \mathrm{R}$

(a)

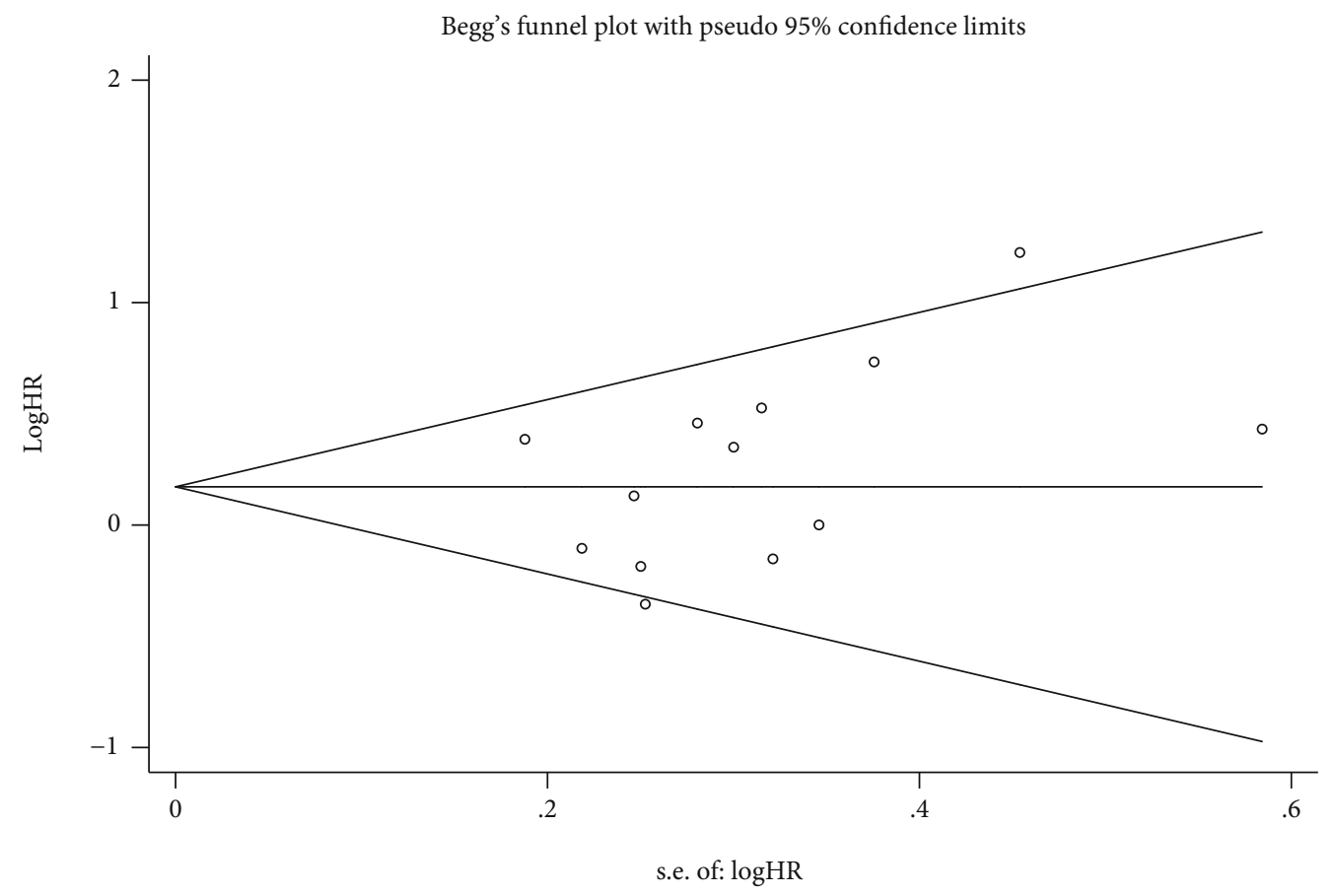

(b)

Figure 6: Continued. 
Begg's funnel plot with pseudo 95\% confidence limits

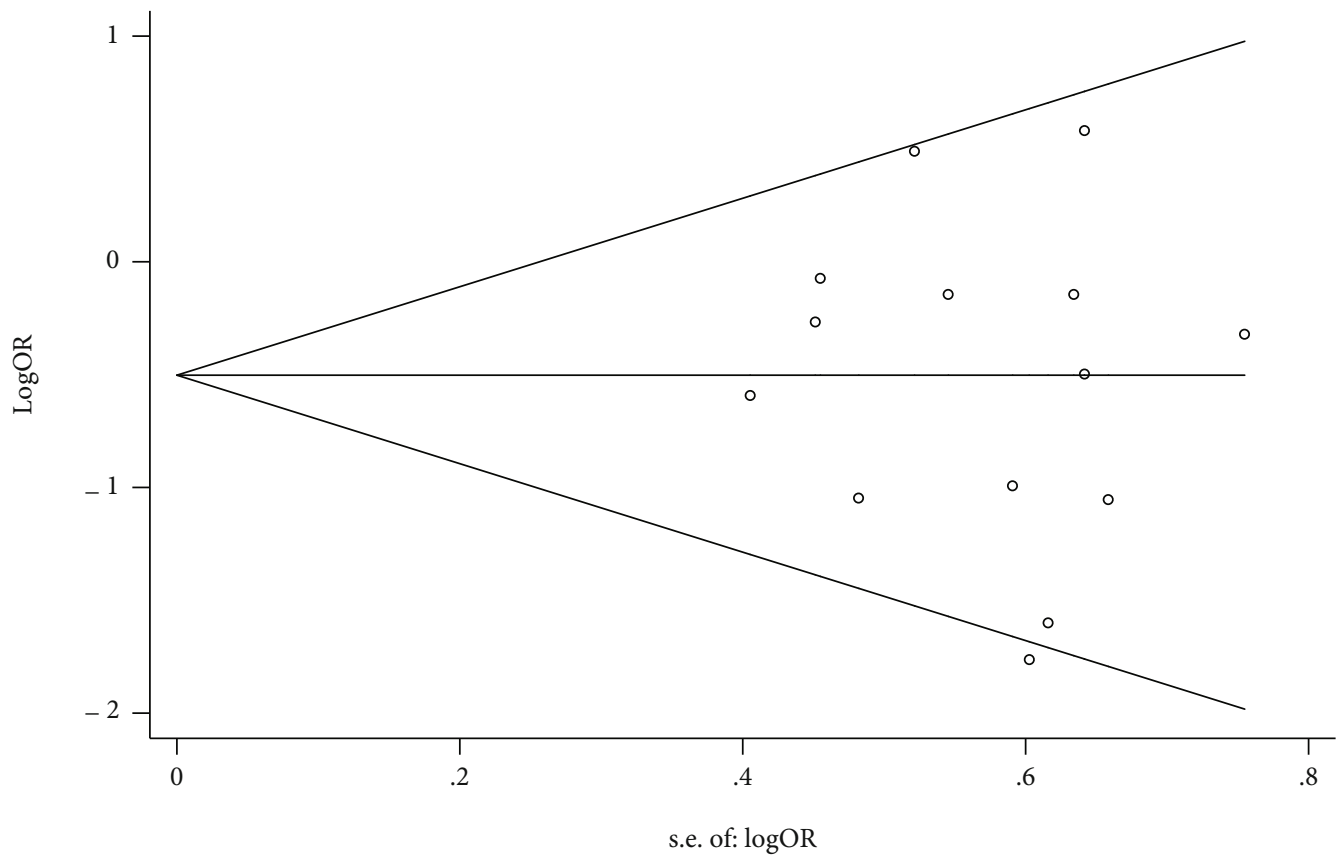

(c)

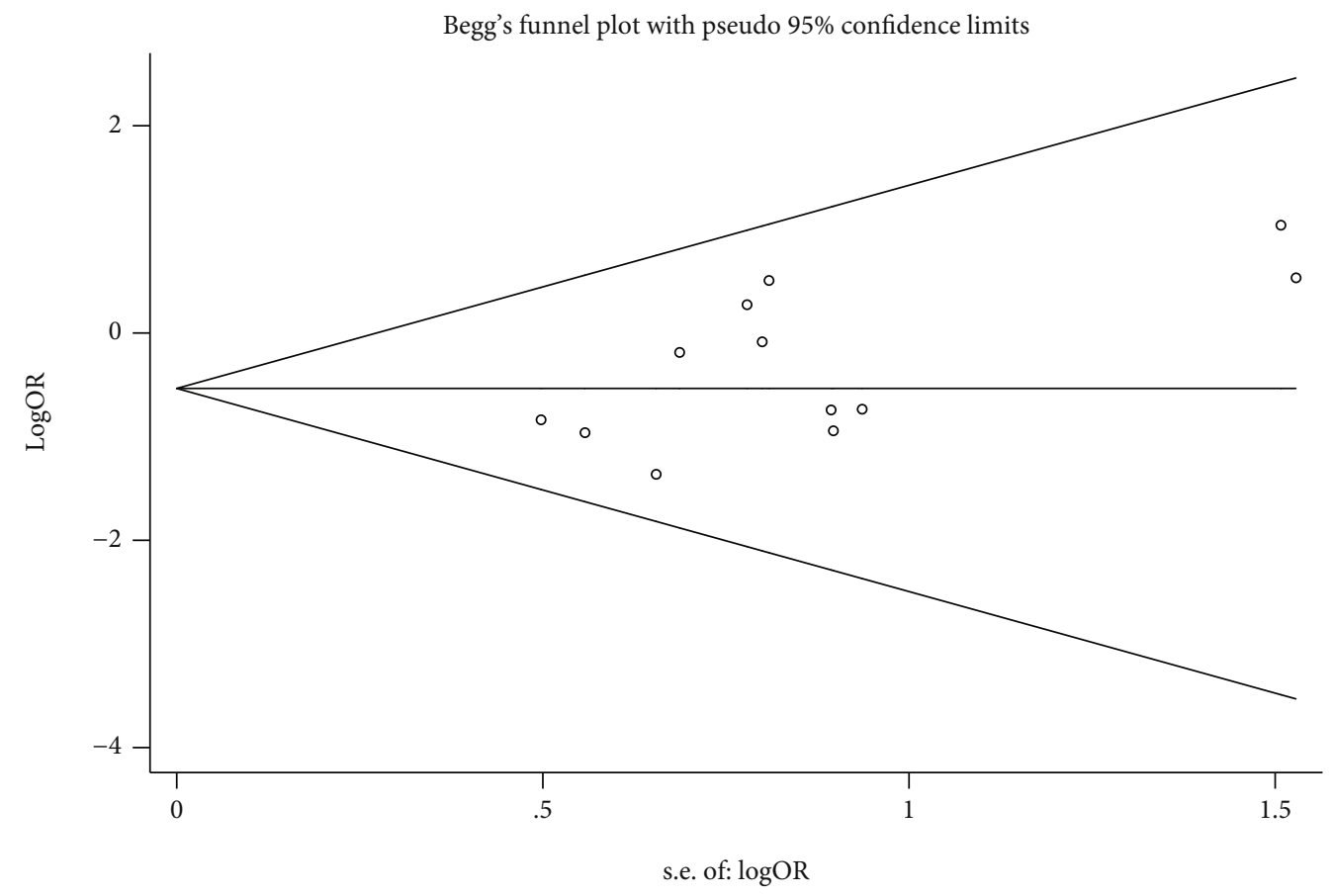

(d)

FIGURE 6: Funnel plots for progression-free survival (a), overall survival (b), objective response rate (c), and disease control rate (d).

sample size (3003 EGFR-mutant NSCLC patients) compared to the previous ones by adding more recent publications. Thirdly, we applied a random effects model to all the pooled analyses regardless of between-study heterogeneity, considering that potential sources of heterogeneity, including genetic background, clinicopathological features, or the other possible confounders, may vary among included studies. This generates more conservative results and wider confidence intervals compared with using a fixed effects model. In the present study, we found that BIM deletion polymorphism was significantly associated with clinical and survival outcomes in EGFR-mutant NSCLC patients, especially in the Chinese population which has not been revealed by previous meta-analyses. 
However, our study has several limitations. Firstly, almost all of the included studies were retrospectively designed, which unavoidably introduced bias. More prospective studies are needed in the future. Secondly, most of included studies were investigating the first-generation EGFR-TKIs, and only one study for osimertinib, a thirdgeneration EGFR-TKI with widespread utilization in current clinical practice, was available for our analysis. BIM deletion was associated with shorter PFS and lower ORR in EGFR T790M NSCLC patients treated with osimertinib [45], which needs validation in more populations. Thirdly, most of the studies were performed in Asian populations since the BIM deletion was rare in Caucasian populations, which limited the application of our results.

\section{Conclusions}

In conclusion, the $2903 \mathrm{bp}$ deletion polymorphism of BIM is associated with poor response to EGFR-TKIs, primarily the first-generation inhibitors, in EGFR-mutant NSCLC patients. BIM deletion polymorphism can be used as a prognostic marker in this group of patients from Asian populations.

\section{Data Availability}

The data used to support the findings of this study are available from the corresponding author upon request.

\section{Conflicts of Interest}

All authors declare no conflicts of interest.

\section{Supplementary Materials}

Supplementary 1. Supplementary File 1. Supplementary Table 1: results of metaregression analysis.

Supplementary 2. Supplementary File 2: PRISMA 2009 checklist.

\section{References}

[1] F. Bray, J. Ferlay, I. Soerjomataram, R. L. Siegel, L. A. Torre, and A. Jemal, "Global cancer statistics 2018: GLOBOCAN estimates of incidence and mortality worldwide for 36 cancers in 185 countries," CA: a Cancer Journal for Clinicians, vol. 68, no. 6, pp. 394-424, 2018.

[2] D. S. Dizon, L. Krilov, E. Cohen et al., "Clinical cancer advances 2016: annual report on progress against cancer from the American Society of Clinical Oncology," Journal of Clinical Oncology, vol. 34, no. 9, pp. 987-1011, 2016.

[3] B. Besse, A. Adjei, P. Baas et al., "2nd ESMO Consensus Conference on Lung Cancer: non-small-cell lung cancer first-line/second and further lines of treatment in advanced disease," Annals of Oncology, vol. 25, no. 8, pp. 14751484, 2014.

[4] J. G. Paez, P. A. Jänne, J. C. Lee et al., "EGFR mutations in lung cancer: correlation with clinical response to gefitinib therapy," Science, vol. 304, no. 5676, pp. 1497-1500, 2004.
[5] T. J. Lynch, D. W. Bell, R. Sordella et al., "Activating mutations in the epidermal growth factor receptor underlying responsiveness of non-small-cell lung cancer to gefitinib," The New England Journal of Medicine, vol. 350, no. 21, pp. 2129-2139, 2004.

[6] S. Tracy, T. Mukohara, M. Hansen, M. Meyerson, B. E. Johnson, and P. A. Janne, "Gefitinib induces apoptosis in the EGFRL858R non-small-cell lung cancer cell line H3255," Cancer Research, vol. 64, no. 20, pp. 7241-7244, 2004.

[7] Y. L. Wu, C. Zhou, C. P. Hu et al., "Afatinib versus cisplatin plus gemcitabine for first-line treatment of Asian patients with advanced non-small-cell lung cancer harbouring _EGFR_ mutations (LUX-Lung 6): an open-label, randomised phase 3 trial," The Lancet Oncology, vol. 15, no. 2, pp. 213-222, 2014.

[8] L. V. Sequist, J. C. Yang, N. Yamamoto et al., "Phase III study of afatinib or cisplatin plus pemetrexed in patients with metastatic lung adenocarcinoma with EGFR mutations," Journal of Clinical Oncology, vol. 31, no. 27, pp. 3327-3334, 2013.

[9] T. S. Mok, Y. L. Wu, S. Thongprasert et al., "Gefitinib or carboplatin-paclitaxel in pulmonary adenocarcinoma," The New England Journal of Medicine, vol. 361, no. 10, pp. 947957, 2009.

[10] T. S. Mok, Y. L. Wu, M. J. Ahn et al., "Osimertinib or platinum-pemetrexed in EGFR T790M-positive lung cancer," The New England Journal of Medicine, vol. 376, no. 7, pp. 629-640, 2017.

[11] S. S. Ramalingam, J. Vansteenkiste, D. Planchard et al., "Overall survival with osimertinib in untreated, EGFR-mutated advanced NSCLC," The New England Journal of Medicine, vol. 382, no. 1, pp. 41-50, 2020.

[12] J. C. Soria, Y. Ohe, J. Vansteenkiste et al., "Osimertinib in UntreatedEGFR-Mutated advanced non-small-cell lung cancer," The New England Journal of Medicine, vol. 378, no. 2, pp. 113-125, 2018.

[13] S. Kobayashi, T. J. Boggon, T. Dayaram et al., "EGFRMutation and resistance of non-small-cell lung cancer to gefitinib," The New England Journal of Medicine, vol. 352, no. 8, pp. 786792, 2005.

[14] A. Ahsan, "Mechanisms of resistance to EGFR tyrosine kinase inhibitors and therapeutic approaches: an update," Advances in Experimental Medicine and Biology, vol. 893, pp. 137-153, 2016.

[15] C. Lazzari, V. Gregorc, N. Karachaliou, R. Rosell, and M. Santarpia, "Mechanisms of resistance to osimertinib," Journal of Thoracic Disease, vol. 12, no. 5, pp. 2851-2858, 2020.

[16] R. J. Youle and A. Strasser, "The BCL-2 protein family: opposing activities that mediate cell death," Nature Reviews. Molecular Cell Biology, vol. 9, no. 1, pp. 47-59, 2008.

[17] D. B. Costa, B. Halmos, A. Kumar et al., "BIM mediates EGFR tyrosine kinase inhibitor-induced apoptosis in lung cancers with oncogenic EGFR mutations," PLoS Medicine, vol. 4, no. 10, pp. 1669-79; discussion 1680, 2007.

[18] K. P. Ng, A. M. Hillmer, C. T. Chuah et al., “A common BIM deletion polymorphism mediates intrinsic resistance and inferior responses to tyrosine kinase inhibitors in cancer," Nature Medicine, vol. 18, no. 4, pp. 521-528, 2012.

[19] J. H. Lee, Y. L. Lin, W. H. Hsu et al., "Bcl-2-Like Protein 11 Deletion Polymorphism Predicts Survival in Advanced NonSmall-Cell Lung Cancer," Journal of Thoracic Oncology, vol. 9, no. 9, pp. 1385-1392, 2014. 
[20] L. Zheng, B. Lin, Z. Song et al., "Relationship between BIM gene polymorphism and therapeutic efficacy in the retreatment of advanced non-small cell lung cancer with tyrosine kinase inhibitor," Zhongguo Fei Ai Za Zhi, vol. 16, no. 12, pp. 632-638, 2013.

[21] S. Y. Liu, J. Y. Zhou, W. F. Li et al., "Concomitant genetic alterations having greater impact on the clinical benefit of EGFRTKIs in EGFR-mutant advanced NSCLC than BIM deletion polymorphism," Clinical and Translational Medicine, vol. 10, no. 1, pp. 337-345, 2020.

[22] F. Wang, X. Y. Diao, X. Zhang et al., "Identification of genetic alterations associated with primary resistance to EGFR-TKIs in advanced non-small-cell lung cancer patients with EGFR sensitive mutations," Cancer Communications (London), vol. 39, no. 1, p. 7, 2019.

[23] J. Y. Lee, B. M. Ku, S. H. Lim et al., "The BIM Deletion Polymorphism and its Clinical Implication in Patients with EGFR-Mutant Non -Small-Cell Lung Cancer Treated with EGFR Tyrosine Kinase Inhibitors," Journal of Thoracic Oncology, vol. 10, no. 6, pp. 903-909, 2015.

[24] J. F. Tierney, L. A. Stewart, D. Ghersi, S. Burdett, and M. R. Sydes, "Practical methods for incorporating summary timeto-event data into meta-analysis," Trials, vol. 8, no. 1, p. 16, 2007.

[25] A. Stang, "Critical evaluation of the Newcastle-Ottawa scale for the assessment of the quality of nonrandomized studies in meta-analyses," European Journal of Epidemiology, vol. 25, no. 9, pp. 603-605, 2010.

[26] N. Karachaliou, J. Codony-Servat, C. Teixidó et al., "BIM and mTOR expression levels predict outcome to erlotinib in EGFR-mutant non-small-cell lung cancer," Scientific Reports, vol. 5, no. 1, article 17499, 2015.

[27] C. Costa, M. A. Molina, A. Drozdowskyj et al., “The impact of EGFR T790M mutations and BIM mRNA expression on outcome in patients with EGFR-mutant NSCLC treated with erlotinib or chemotherapy in the randomized phase III EURTAC trial," Clinical Cancer Research, vol. 20, no. 7, pp. 2001-2010, 2014.

[28] A. C. Faber, R. B. Corcoran, H. Ebi et al., "BIM expression in treatment-naive cancers predicts responsiveness to kinase inhibitors," Cancer Discovery, vol. 1, no. 4, pp. 352-365, 2011.

[29] Y. T. Lin, Y. N. Liu, and J. Y. Shih, "The impact of clinical factors, ALK fusion variants, and BIM polymorphism on crizotinib-treated advanced EML4-ALK rearranged nonsmall cell lung cancer," Frontiers in Oncology, vol. 9, p. $880,2019$.

[30] L. Zhang, T. Jiang, X. Li et al., "Clinical features of Bim deletion polymorphism and its relation with crizotinib primary resistance in Chinese patients with ALK/ROS1 fusion-positive non-small cell lung cancer," Cancer, vol. 123, no. 15, pp. 2927-2935, 2017.

[31] J. Atsumi, K. Shimizu, Y. Ohtaki et al., "Impact of the Bim Deletion Polymorphism on Survival Among Patients With Completely Resected Non-Small-Cell Lung Carcinoma," Journal of global oncology, vol. 2, no. 1, pp. 15-25, 2016.

[32] E. N. Cho, E. Y. Kim, J. Y. Jung et al., "BCL2-like 11 intron 2 deletion polymorphism is not associated with non-small cell lung cancer risk and prognosis," Lung Cancer, vol. 90, no. 1, pp. 106-110, 2015.

[33] J. Yuan, B. Li, N. Zhang et al., "Clinical Implications of the BIM Deletion Polymorphism in Advanced Lung Adenocarcinoma
Treated With Gefitinib," Clinical Lung Cancer, vol. 19, no. 4, pp. e431-e438, 2018.

[34] S. X. Soh, F. J. Siddiqui, J. C. Allen et al., "A systematic review and meta-analysis of individual patient data on the impact of the BIM deletion polymorphism on treatment outcomes in epidermal growth factor receptor mutant lung cancer," Oncotarget, vol. 8, no. 25, pp. 41474-41486, 2017.

[35] J. Zhong, Z. X. Li, J. Zhao et al., "Analysis of BIM (BCL-2 like 11 gene) deletion polymorphism in Chinese non-small cell lung cancer patients," Thorac Cancer, vol. 5, no. 6, pp. 509516, 2014.

[36] M. Zhao, Y. Zhang, W. Cai et al., "The Bim deletion polymorphism clinical profile and its relation with tyrosine kinase inhibitor resistance in Chinese patients with non-small cell lung cancer," Cancer, vol. 120, no. 15, pp. 2299-2307, 2014.

[37] J. Xia, H. Bai, B. Yan et al., "Mimicking the BIM BH3 domain overcomes resistance to EGFR tyrosine kinase inhibitors in EGFR-mutant non-small cell lung cancer," Oncotarget, vol. 8, no. 65, pp. 108522-108533, 2017.

[38] S. G. Wu, Y. N. Liu, C. J. Yu, P. C. Yang, and J. Y. Shih, “Association of BIM deletion polymorphism with intrinsic resistance to EGFR tyrosine kinase inhibitors in patients with lung adenocarcinoma," JAMA Oncology, vol. 2, no. 6, pp. 826-828, 2016.

[39] S. Sun, H. Yu, H. Wang et al., "Exploratory cohort study and meta-analysis of BIM deletion polymorphism in patients with epidermal growth factor receptor-mutant non-small-cell lung cancer treated with epidermal growth factor receptor tyrosine kinase inhibitors," Oncotargets and Therapy, vol. 10, pp. 19551967, 2017.

[40] K. Qian, Y. Zhang, and X. Zhi, "Retrospective study of efficacy in BIM gene polymorphism on first-line EGFR-TKIs treatment for advanced lung adenocarcinoma," Zhongguo Fei Ai Za Zhi, vol. 20, no. 8, pp. 543-548, 2017.

[41] J. K. Lee, J. Y. Shin, S. Kim et al., "Primary resistance to epidermal growth factor receptor (EGFR) tyrosine kinase inhibitors (TKIs) in patients with non-small-cell lung cancer harboring TKI- sensitive EGFR mutations: an exploratory study," Annals of Oncology, vol. 24, no. 8, pp. 2080-2087, 2013.

[42] K. Isobe, Y. Hata, N. Tochigi et al., "Clinical Significance of BIM Deletion Polymorphism in Non -Small-Cell Lung Cancer with Epidermal Growth Factor Receptor Mutation," Journal of Thoracic Oncology, vol. 9, no. 4, pp. 483-487, 2014.

[43] P. Incharoen, C. Charonpongsuntorn, S. Saowapa et al., "Role of BIM deletion polymorphism and BIM expression as predictive biomarkers to maximize the benefit of EGFR-TKI treatment in EGFR-positive NSCLC," Asian Pacific Journal of Cancer Prevention, vol. 20, no. 12, pp. 3581-3589, 2019.

[44] on behalf of the CLICaP, A. F. Cardona, L. Rojas et al., "BIM deletion polymorphisms in Hispanic patients with non-small cell lung cancer carriers of EGFR mutations," Oncotarget, vol. 7, no. 42, pp. 68933-68942, 2016.

[45] X. Li, D. Zhang, B. Li et al., "Clinical implications of germline BCL2L11 deletion polymorphism in pretreated advanced NSCLC patients with osimertinib therapy," Lung Cancer, vol. 151, pp. 39-43, 2021.

[46] R. Ariyasu, N. Yanagitani, K. Tadokoro et al., "Efficacy of EGFR tyrosine kinase inhibitors in patients having EGFRactivating mutations with or without BIM polymorphisms," Cancer Chemotherapy and Pharmacology, vol. 86, no. 4, pp. 517-525, 2020. 
[47] T. K. Ko, H. S. Chin, C. T. Chuah et al., "The BIM deletion polymorphism: a paradigm of a permissive interaction between germline and acquired TKI resistance factors in chronic myeloid leukemia," Oncotarget, vol. 7, no. 3, pp. 2721-2733, 2016.

[48] A. Tanimoto, S. Takeuchi, S. Arai et al., "Histone Deacetylase 3 Inhibition Overcomes BIM Deletion PolymorphismMediated Osimertinib Resistance in EGFR- Mutant Lung Cancer," Clinical Cancer Research, vol. 23, no. 12, pp. 31393149, 2017.

[49] T. Nakagawa, S. Takeuchi, T. Yamada et al., "EGFR-TKI resistance due to BIM polymorphism can be circumvented in combination with HDAC inhibition," Cancer Research, vol. 73, no. 8, pp. 2428-2434, 2013.

[50] S. Takeuchi, T. Hase, S. Shimizu et al., "Phase I study of vorinostat with gefitinib in BIM deletion polymorphism/epidermal growth factor receptor mutation double-positive lung cancer," Cancer Science, vol. 111, no. 2, pp. 561-570, 2020.

[51] M. E. Morrison, T. L. Palenski, N. Jamali, N. Sheibani, and C. M. Sorenson, "Modulation of vascular cell function by bim expression," International journal of cell biology, vol. 2013, Article ID 297537, 15 pages, 2013.

[52] C. Grutzmacher, S. Park, T. L. Elmergreen et al., "Opposing effects of bim and bcl-2 on lung endothelial cell migration," American Journal of Physiology. Lung Cellular and Molecular Physiology, vol. 299, no. 5, pp. L607-L620, 2010.

[53] S. Wang, I. S. Zaitoun, R. P. Johnson et al., "Bim expression in endothelial cells and pericytes is essential for regression of the fetal ocular vasculature," PLoS One, vol. 12, no. 5, article e0178198, 2017.

[54] K. Nakagawa, E. B. Garon, T. Seto et al., "Ramucirumab plus erlotinib in patients with untreated, EGFR -mutated, advanced non-small-cell lung cancer (RELAY): a randomised, doubleblind, placebo-controlled, phase 3 trial," The Lancet Oncology, vol. 20, no. 12, pp. 1655-1669, 2019.

[55] Z. Chen, S. Jiang, X. Li et al., "Efficacy and safety of antiangiogenic drugs combined with erlotinib in the treatment of advanced non-small cell lung cancer: a meta-analysis of randomized clinical trials," Annals of Palliative Medicine, vol. 10, no. 3, pp. 2687-2698, 2021.

[56] A. F. Cardona, C. Ordóñez-Reyes, A. Ruiz-Patiño et al., "EGFR inhibitors plus bevacizumab are superior than EGFR inhibitors alone as first-line setting in advanced NSCLC with EGFR mutations and BIM deletion polymorphisms (BIM-CLICaP)," JCO Precision Oncology, vol. 5, no. 5, pp. 839-848, 2021.

[57] J. R. Lechien, J. W. Hsieh, and S. Saussez, "Unusual case of chronic maxillary rhinosinusitis," Ear, Nose, \& Throat Journal, vol. 96, no. 3, pp. 100-104, 2017.

[58] W. Su, X. Zhang, X. Cai, M. Peng, F. Wang, and Y. Wang, "BIM deletion polymorphism predicts poor response to EGFR-TKIs in nonsmall cell lung cancer: an updated metaanalysis," Medicine (Baltimore), vol. 98, no. 10, article e14568, 2019.

[59] Q. Zou, P. Zhan, T. Lv, and Y. Song, "The relationship between BIM deletion polymorphism and clinical significance of epidermal growth factor receptor-mutated non-small cell lung cancer patients with epidermal growth factor receptortyrosine kinase inhibitor therapy: a meta-analysis," Transl Lung Cancer Res, vol. 4, no. 6, pp. 792-796, 2015.
[60] W. Nie, X. Tao, H. Wei, W. S. Chen, and B. Li, "The BIM deletion polymorphism is a prognostic biomarker of EGFR-TKIs response in NSCLC: a systematic review and meta-analysis," Oncotarget, vol. 6, no. 28, pp. 25696-25700, 2015.

[61] W. F. Huang, A. H. Liu, H. J. Zhao, H. M. Dong, L. Y. Liu, and S. X. Cai, "BIM gene polymorphism lowers the efficacy of EGFR-TKIs in advanced nonsmall cell lung cancer with sensitive EGFR mutations: a systematic review and meta-analysis," Medicine (Baltimore), vol. 94, no. 33, article e1263, 2015. 